empfohlen. Die befarietene Siluppe if nur eine Mlodification be= reitż andDerwärtż befđriebener Siluppen, Dürfte aber zu empfehlen fein.

Fử alle Fnđgenoffen, welde fich fữ bie Entwidflung Der Taxationswifienidaft intereffiren und nidgt etwa iđop im Befibe Der. (1) runert'fकen forftliden Blätter find, fann die vorliegende fleine Sdrift empfohlen werden.

\title{
Nö 12.
}

Die $\mathfrak{B a l}$ afduepfe und ihre $3 a g b$. Allen gliten flugs

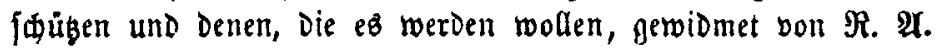
von Benberg. 3'weite Huflage. Berlin 1866. Berlag bon $\Re u=$ Dolph Bärmer. S. 144. \$retô: $54 \mathrm{fr}$.

Die Jagbliteratur mehrt fich bon $\mathfrak{T a g}$ zu $\mathfrak{Z}$ ag und follen es auc nur Compilationen auz andern Эagdwerfen fein. Davon gibt

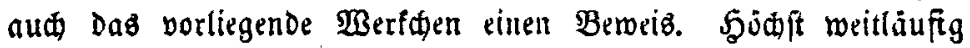

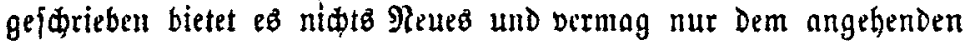
S̈äger einige Belehrung zu bieten, Die er jeDod in gröberen ३agD: werfen aud findet. Darnus geht hervor, Dak wir es dem wabren Baibmann jum 2untaufe gerabe nidyt empfehten nö̈ten.

(1). v. \&.

\section{3ur 2Barnung.}

Im Noventberbefte von 1865 Diejer Blätter findet fted ein mit

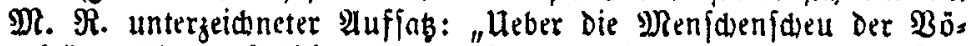

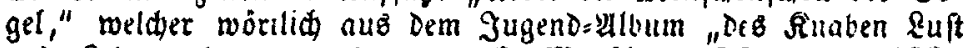
und Rebre", heraużgegeben von 5. . Ma a $\{$ iu b, IV. Band, 1862 (B)logau bei glemming) abgefatricben ift. Der cigentlde Berfaffer

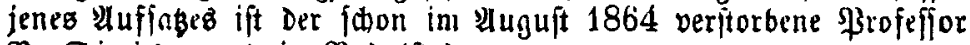
B. Eigiż mut no in Siudolftadt.

Benn wir unz nun aud für diefesmal Darnuf beịtranften,

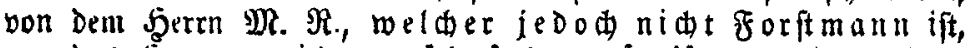
mur Dab 5ूonorar wieder jurüđjufordern, fo tönnen wir es Dod nid)t unterlaijen, Darauf aufmerffam zu machen, DaE, wenn fit由 mògliderweife unter unjerer Reiactiull ein ảhntiduer Fall ereignen Follte, wir Dann son allen Der Redaction in foldben Fällen zuftehen= Den Redten vollen (Gebrauty madjen werden.

Die Redaction. Berantwortlider Revactelr: Dr. Fr. Baur. Broieffor an ber Mfabemie Sobengeim.
Druf und Berlas yon E. Edoweiderbart in Etuttgart. 